(C) 1980. The Genetical Society of Great Britain

\title{
REGULATORY GENE ADAPTATION: AN EVOLUTIONARY MODEL
}

\author{
PHILIP W. HEDRICK and JOHN F. McDONALD \\ Division of Biological Sciences, University of Kansas, Lawrence, KS 66045, and \\ Department of Genetics; lowa State University, Ames, IA 50010
}

Received 8.x.79

\begin{abstract}
SUMMARY
There is increasing support for the notion that changes in regulatory loci have played a major role in eukaryotic evolution. Assuming a model of genetic regulation based upon presently accepted views of the organisation of the eukaryotic genome and basic models of evolutionary genetics, one can provide a context for speculation about the advantages and disadvantages of adaptation via regulatory genes. As additional information is obtained on particular regulatory systems, the evolutionary genetic model can be modified and expanded.
\end{abstract}

\section{INTRODUCTION}

A NUMBER of authors have suggested that changes in genetic regulation are of major importance in eukaryotic evolution (e.g., Wallace, 1963; Zuckerlandl, 1963; Stebbins, 1969; Wilson, 1975; Valentine and Campbell, 1975). Both indirect and direct evidence have been mustered in support of this view. Much of the indirect evidence is based upon the apparent lack of correlation, at least in some lineages, between the rate of base substitution at loci determining protein structure and the rate of change on the evolutionary significant phenotypic level (Wilson, 1975; however, see Radinsky, 1978). For example, King and Wilson (1975) found that humans and chimpanzees are extremely similar with regard to the structure of their proteins. Indeed the degree of similarity existing between these species is equivalent to what had previously been found between morphologically indistinguishable sibling species of many other groups of organisms ranging from vertebrates to Drosophila (Selander and Johnson, 1973; Avise, 1974, 1976). Despite this remarkable similarity in protein structure, the morphological and behavioural characteristics of chimpanzees and humans are great enough to place them in different zoological families. King and Wilson concluded from this that many of the major evolutionary differences between chimp and man may be due to changes in genetic regulation.

Most of the direct evidence for the potential importance of regulatory gene change in adaptive evolution comes from a series of laboratory experiments in which organisms are forced to adapt to novel environmental challenges and the genetic basis of their response is carefully monitored. For example, Lin et al. (1976) have summarised a number of studies where prokaryotes have been forced to adapt to novel environments such as a new carbon source. The primary event permitting such adaptations is often found to involve a regulatory mutation. Recently, McDonald et al. (1977) reported the results of a similar type of experiment with Drosophila melanogaster. Examining a population selected for 28 generations for 
increased tolerance to ethanol, they found that the selected flies exhibited increased alcohol dehydrogenase activity levels. In addition it was found that the increased activity in the selected population was apparently not the direct result of a change in the amino acid sequence of the ADH enzyme itself, but rather was caused by the presence of more ADH molecules in the resistant flies. In other words, adaptive change had taken place at one or more genes regulating the amount of ADH. Such regulatory variation for $\mathrm{ADH}$ as well as other enzyme systems has been reported elsewhere (e.g., Ward, 1975; Barnes and Birley, 1978; McDonald and Ayala, 1978; LaurieAhlberg et al., 1980) and these factors appear to be located throughout the Drosophila genome.

Overall, then, there is a growing body of evidence that regulatory genes are important in evolution. Surprisingly, no one has systematically investigated evolutionary genetic models to determine under what conditions regulatory gene adaptation might be advantageous as compared with adaptation via genes involved in non-regulatory functions, and vice versa. In order to do this, one must make assertions about the likely phenotypic effect of regulatory genes. A model of this type, taken in conjunction with theoretical evolutionary genetics, provides a context for speculation about the advantages and disadvantages of adaptation via regulatory genes.

\section{(i) What is a "regulatory gene"?}

Before an evolutionary genetic model can be constructed it is essential to establish what is meant by the term "regulatory gene". A universally acceptable definition of "regulatory gene" probably does not exist. This is in part due to the fact that our knowledge of the regulatory process is as yet incomplete and in part to the fact that the varied definitions that do exist often reflect particular research interests. For example, biochemicallyoriented investigators of ten view regulatory genes from a purely mechanistic perspective. In this genre, regulatory genes are often envisaged as "receptor sites" where repressor or inducer substances (themselves possibly the product of designated "regulatory genes") differentially bind and thus, in one way or another, affect the attachment and/or movement of RNA polymerase along the DNA molecule. The term "structural gene" is generally reserved for loci which code for protein products.

More classically oriented developmental biologists, on the other hand, generally employ what may be characterised as a functional definition of regulatory genes. For them regulatory or control genes are those which exert an influence over the timing or expression of a specific phenotype or developmental pattern. In so far as the particular phenotype or developmental pattern is an enzymatic activity or known to be under the direct control of a specific enzymatic activity, regulatory genes can be functionally defined as loci which affect the activity of the particular enzyme under consideration (MacIntyre and O'Brien, 1976).

Although both of these perspectives are equally legitimate within appropriate contexts, confusion might, in some instances, arise if the term "regulatory gene" is employed in one sense but interpreted in another. For example, not all genetic control of developmental processes need be at the transcription level, involving the attachment or movement of RNA polymerase. It is certainly possible that the protein product of one locus can have 
as its sole function the activation of the product of another genetic locus. Such activations may be carried out at a post-translational level involving the chemical modification of a pre-existing protein or at a post-transcriptional level involving the modification of nascent mRNA. A gene which codes for an enzyme having such a modifying role may legitimately be dubbed "regulatory" in a functional sense while remaining "structural" in a mechanistic sense. Thus although there may not be a single correct definition of the term regulatory gene, there may well be a single appropriate definition within a given context.

We have adopted a view in which the genome is operationally bisected into two classes of genes. Regulatory genes are defined as those loci whose primary role is to control the timing or expression of the products of other genes. Loci which specify cellular products directly involved in metabolic or structural functions are referred to as producer genes. From this evolutionary appropriate perspective, producer genes are by nature regulated rather than regulatory while regulatory genes are by nature regulatory rather than regulated (Britten and Davidson, 1969).

\section{THE MODEL}

\section{(i) General properties}

Information about the action and interaction of regulatory genes in eukaryotes is incomplete, although the general model proposed by Britten and Davidson (1969) encompasses many of the important aspects of gene control. We will use a modification of the Britten and Davidson model which is given in fig. 1 . In this model there are producer genes which code

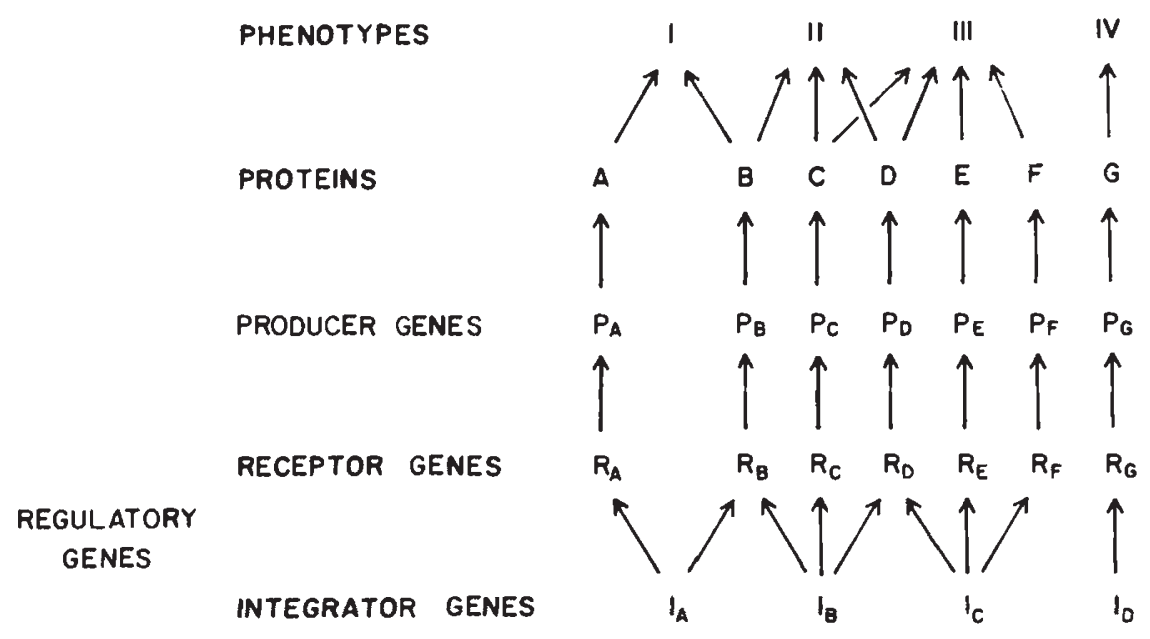

FIG. 1.-A model of gene regulation in eukaryotes.

for protein products which can be grouped according to the phenotypic (metabolic or structural) function(s) with which they are involved. Regulatory genes coordinate and control the synthesis and/or activation of the producer gene products. We are not concerned with the validity of the details of this model but only with the following general characteristics. 
(a) The model of gene regulation is hierarchical with regulatory genes generally affecting the amount or activity of gene product coded for at two or more producer genes.

As suggested above, there are several possible levels at which regulatory genes can control or modify the activity of the products of other genes. First, they may be involved in the control of transcription such as the "integrator genes" found in prokaryotes. Secondly, they may act post-transcriptionally either by affecting the maturation of the HnRNA, the movement of RNA to the cytoplasm, or translation itself. Finally, they may modify the gene product post-translationally. Genes operating at these three levels could be termed pre-transcriptional, post-transcriptional and post-translational regulatory genes, respectively. Obviously, therefore, genes which are operationally classified as "regulatory" are mechanistically speaking quite a heterogeneous class.

There is a growing body of experimental evidence which supports a hierarchical genomic structure in eukaryotes (Hood et al., 1975). Due to its propensity for genetic analysis much of this work has been carried out in Drosophila (e.g., Ashburner, 1970; Lewis, 1978). For example, detailed analyses have been made of a variety of major developmental mutants (homoeotic) in Drosophila (Baker, 1978). In each case the data point to the hierarchical involvement of a series of genetic elements. Genes involved early in the developmental process seem have a very broad phenotypic effect while genes exerting their influence later seem to be more specific in the traits they influence. Garcia-Bellido $(1975,1977)$ has recently incorporated these findings into a hierarchical model of genetic control which is in its essentials not unlike the Britten-Davidson type model employed in this paper.

(b) Phenotypic values are a function of the amount and type of protein coded for by several loci.

This is simply an assertion that most phenotypic level structures and functions involve the products of more than one producer gene.

(c) Changes in phenotypic structures and/or functions can be brought about by alternative genetic strategies involving different sets or arrangements of producer genes, regulatory genes, or alternative combinations of both.

Genetic variation is the sine qua non of evolution. The existence of variation for genes processing functionally different properties (e.g., regulatory versus producer) implies the existence of alternative genetic strategies of adaptation.

\section{(ii) Advantage of regulatory gene change}

The hierarchical nature of the above model dictates that, all else remaining equal, regulatory genes will have a larger phenotypic effect per locus than producer genes. This fact leads to specific predictions concerning the likely adaptive potential of changes at regulatory versus producer gene loci over evolutionary time.

To illustrate how having a larger selective coefficient per locus would be advantageous, imagine a simple model consisting of one regulatory gene which controls the rate of transcription at two producer genes. Assume that adaptation can occur either by a change in frequency of the alleles at the regulatory locus $R$ or alleles at the two producer loci $(A$ and $B)$. In other 
words, a change at the regulatory gene from $R_{1} R_{1} A_{1} A_{1} B_{1} B_{1}$ to $R_{2} R_{2} A_{1} A_{1} B_{1} B_{1}$ increases the fitness from 1 to $1+s_{1}$ and a change at the two producer loci from $R_{1} R_{1} A_{1} A_{1} B_{1} B_{1}$ to $R_{1} R_{1} A_{2} A_{2} B_{2} B_{2}$ increases the fitness from 1 to $1+s_{2}$. If these two alternatives give the same selective advantage, i.e., $s_{1}=s_{2}$, then the selective advantage per locus is higher for the regulatory avenue. In this case, both adapted populations would be asymptotically the same as far as adaptation, but the time taken to become adapted differs greatly.

An example is given in fig. 2 where $s_{1}=s_{2}=0.2$ and the initial frequency of $R_{2} A_{1} B_{1}$ is $0 \cdot 01$ for the regulatory model. For the non-regulatory model, the initial frequencies of the gametes $R_{1} A_{1} B_{1}, R_{1} A_{1} B_{2}, R_{1} A_{2} B_{1}$, and $R_{1} A_{2} B_{2}$ are $0.98,0 \cdot 01,0 \cdot 01$, and 0.0 , and $A$ and $B$ are unlinked. Additivity between alleles and equal and additive effects for the producer loci are assumed. Notice in fig. 2 that the mean fitness of the regulatory option increases much more quickly so that when it had changed 50 and 90 per cent of the possible amount, the population adapting via producer genes had adapted only 10 and 47 per cent, respectively, of the possible amount (broken lines).

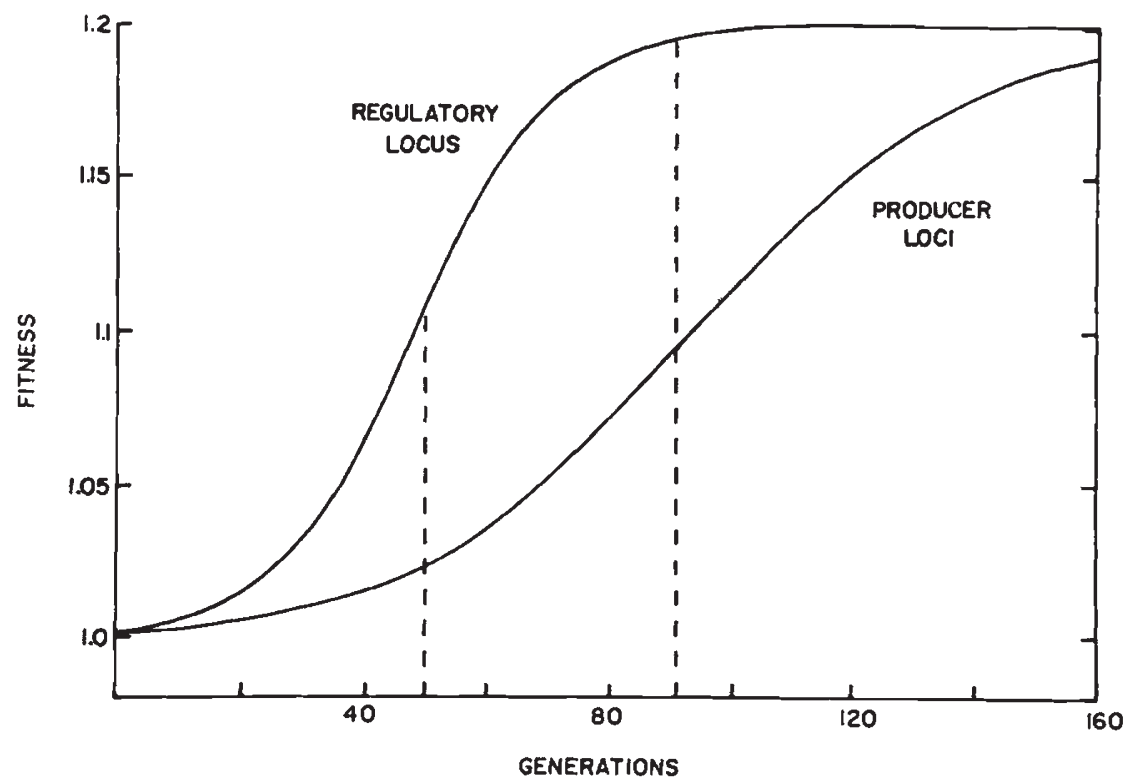

FIG. 2.-A comparison of the change in fitness for an example where a regulatory locus has a larger per-locus effect than two producer loci.

This differential rate of response can be understood by calculation of the initial additive genetic variance for both models. It can be shown that with gametic equilibrium (random association of alleles at different loci) and additivity between loci, that the initial additive genetic variance for the structural model is half that of the regulatory model. Since the increase in fitness (or phenotype) per generation is nearly equal to the amount of additive genetic variance (Fisher, 1958), it follows that the rate of response for the regulatory gene model would be faster. 
A rapid phenotypic response would most likely be selectively advantageous when a population or species is faced with a rapid and dramatic environmental change. Although dramatic environmental changes occurring temporarily over a species' range are possible, the more probable cause of rapid environmental challenges are likely to be involved with the process of niche expansion and consequent adaptive radiation (Simpson, 1944, 1953). One logical historical consequence of our model, then, is that species which have evolved rapidly with the sudden appearance of novel and dramatic phenotypes are likely to differ significantly on the regulatory gene level.

The prediction that regulatory gene change will be favoured in situations requiring rapid and dramatic adaptation also follows from other likely characteristics of regulatory loci. Since these special properties lie outside the context of hierarchical genomic organisation, they will be presented as an adjunct to the model later in the paper.

\section{(iii) Advantage of non-regulatory gene change}

In the above section, we predicted that regulatory gene change would be selectively favoured over producer gene change when a population is confronted with a sudden and substantial environmental stress. There may, however, be situations when regulatory gene change is not as adaptive as changes at producer loci. The example we will develop here is a situation where there is a gradual environmental change in which the best adaptive strategy is to genetically track this environmental trend as closely as possible. If a large number of producer loci each contribute a small effect, there would be better tracking of the environmental change due to the fact that there is less phenotypic variation around the optimum. In general, in situations where "fine tuning" adaptation is the optimal strategy, producer gene change should be favoured.

To illustrate how regulatory genes may not be able to track a slow environmental change as effectively as producer genes, let us use an optimum selection model of Wright (1969). In this model, the fitness of a particular genotype is a function of its squared deviation from the optimum on some underlying scale, for example, enzyme activity. Assume the fitness of genotype $i$ is

$$
w_{i}=1-t\left(V_{i}-V_{\mathrm{opt}}\right)^{2}
$$

where $t$ is a constant indicating the strength of selection and $V_{i}$ and $V_{\text {opt }}$ are the values of genotype $i$ and the optimum on the underlying scale, respectively. The mean fitness is then

$$
\bar{w}=\sum f_{i} w_{i}
$$

where $f_{i}$ is the frequency of genotype $i$. The genetic load is

$$
L=1-\bar{w}
$$

which is the difference between the mean fitness and the fitness if the population were at the optimum. Again we will compare a one-locus regulatory model and a two-locus producer model. Additivity between alleles and loci is assumed on the underlying scale. On this scale the 
difference between $R_{1} R_{1}$ and $R_{2} R_{2}$ for the one-locus model and the difference between $A_{1} A_{1} B_{1} B_{1}$ and $A_{2} A_{2} B_{2} B_{2}$ for the two-locus model is $s$.

Figure 3 shows the minimum genetic load, assuming gametic equilibrium, for different optimum values for the underlying scale. In this case $s=0 \cdot 2$ and $t$ is 10 . Obviously when the optimum is intermediate, there is the greatest genetic load. Furthermore, the genetic load is much greater for the single-locus regulatory model. The reasons for this difference can be

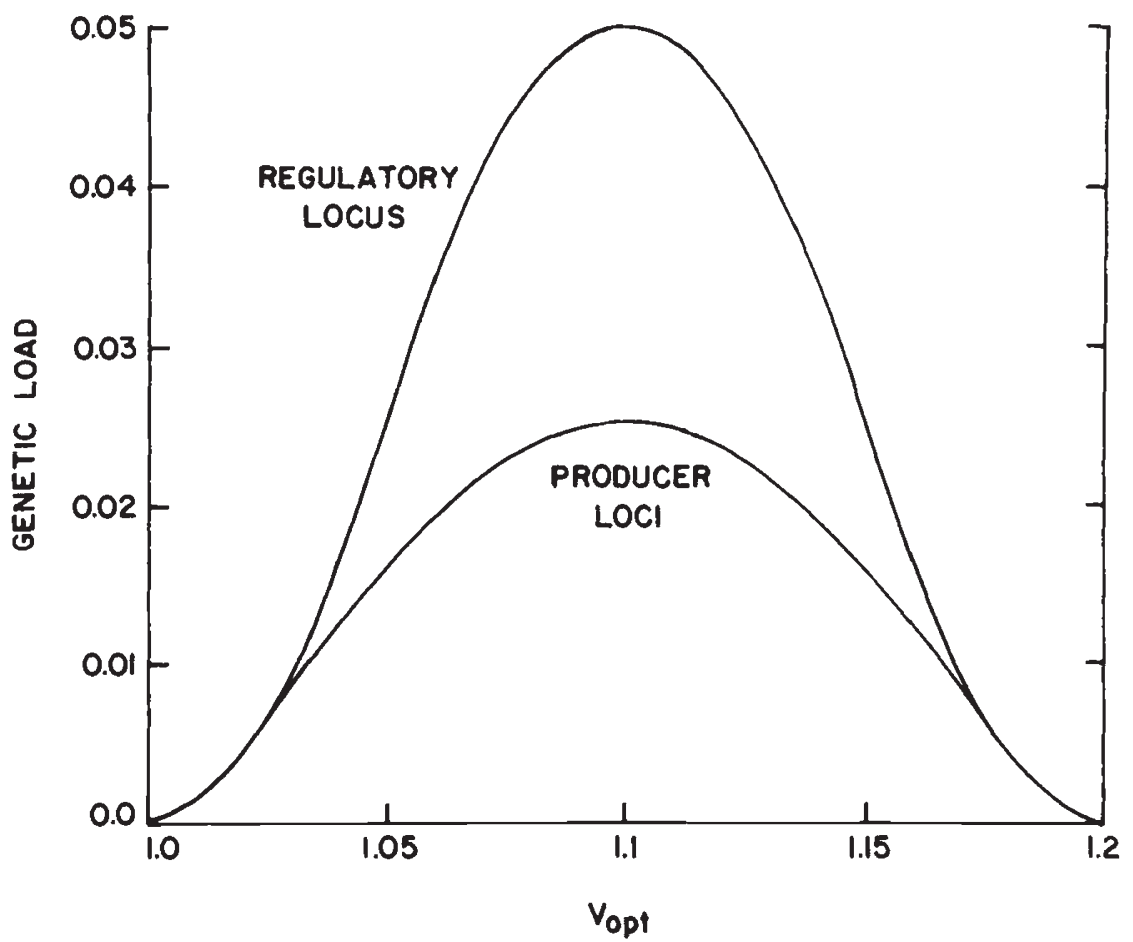

FIG. 3.-A comparison of the genetic load for different optimum values for a regulatory locus and two producer loci.

understood by examining the amount of genetic variance as we did previously. In this case, however, since there is a very slow environmental change, the high amount of variation generated by the single gene model is disadvantageous and results in a large genetic load. As the number of loci increases, the amount of genetic variation and, therefore, the genetic load decreases. We predict from our model, then, that populations or species which have diverged from each other as a result of their gradual adaptation to different environmental settings are likely to display most genetic differentiation on the producer gene level rather than on the regulatory level.

\section{Adjuncts to the model}

(i) Qualitatively different characters

In order to emphasise the importance of "adaptive response time" (i.e., the number of generations required to bring the population to the desired 
adaptive peak) in determining favoured genetic strategies, we assumed that the final fitness value attainable by regulatory gene changes was the same as would be ultimately reached by producer gene change, albeit at a slower rate. In fact, it is likely that certain major changes in the phenotype, especially those involving major modifications in developmental pathways, can only be attained by changes at the regulatory level. For example, there is a growing body of evidence suggesting that the turning on and off of genes in an ordered sequence is necessary for normal development (Hood et al., 1975). A disruption of this sequence may lead to unusual phenotypes or possibly to something approaching the macromutations or "hopeful monsters" of Goldschmidt (1930).

In Drosophila, for example, the $b x^{+}$locus is involved with control of the development of the anterior haltere region of the fly. A mutation at this regulatory locus $\left(b x^{3}\right)$ in the appropriate genetic background $(p b x)$, results in the transformation of the haltere (dorsal metathorax) into a wing (dorsal mesothorax) resulting in a fly with two sets of wings (Lewis, 1978). In Dictyostelium a temperature sensitive regulatory mutant has been identified which can alter the normal developmental profile of the organism such that one life stage (ripple) is dramatically shortened without affecting the normal timing of subsequent stages (Soll, 1979). Kerr et al. (1975) have suggested that the determination of sex and caste in bees is best explained by changes in genetic regulation. In a scheme based upon Britten and Davidson's model, they show how the environment, level of juvenile hormone and a series of regulatory genes might interact to determine the formation of queens, workers, and males.

If, as the above examples suggest, a certain class of major phenotypic changes are the unique result of control gene mutations, there would be additional reason to predict that adaptation to dramatic environmental changes is most likely to involve regulatory genes.

\section{(ii) Unusual gene interactions}

From an examination of fig. 1, it is obvious that models of gene regulation may give examples of gene interactions which may not be common for structural genes. For example, integrator gene $I_{B}$ affects phenotypes I, II and III although in a complex and indirect manner. How this gene, $R_{D}$, and $I_{C}$ interact to determine phenotype III could be a quite complex epistastic situation. Furthermore, the earlier discussion concerning the different levels at which regulatory genes may operate (pre-transcriptional, post-transcriptional, and post-translational) indicates the potential complexity of regulatory gene interaction.

An example of interaction of regulatory genes is given for $\mathrm{ADH}$ activity in Drosophila (McDonald and Ayala, 1978). In this study, different second and third chromosomes were substituted and the activity of $\mathrm{ADH}$ was measured for various combinations. It is assumed that there is at least one regulatory locus on the second chromosome (perhaps a receptor region adjacent to the $A d h$ structural locus; see, for example, Thompson et al., 1977; Maroni, 1978) and at least one regulatory locus on the third chromosome since the amount of ADH is affected by both chromosomes. The mean activities for one example with doubly homozygous chromosomes are given in table 1 . It is obvious by looking at the relative values that there 
TABLE 1

The mean ADH activities and their standard errors along with their relative values (in parentheses) calculated from an example from McDonald and Ayala (1978) where different chromosomes in $\mathrm{D}$. melanogaster were made homozygous

Chromosome II

\begin{tabular}{cccc} 
& & \multicolumn{1}{c}{$I F / I F$} & $3 S / 3 S$ \\
Chromosome III & $2 F / 2 F$ & $25 \cdot 7 \pm 0 \cdot 7(1 \cdot 0)$ & $7 \cdot 0 \pm 0 \cdot 2(0 \cdot 27)$ \\
& $I F / I F$ & $18 \cdot 4 \pm 0 \cdot 3(0 \cdot 72)$ & $11 \cdot 0 \pm 0 \cdot 3(0 \cdot 43)$
\end{tabular}

is interchromosomal interaction. For example, the marginal means would not indicate that $3 S / 3 S, 2 F / 2 F$ would have the lowest relative activity. Barnes and Birley (1978) have also examined ADH activity for different chromosomal combinations. Using an analysis of variance, they found a significant interaction (epistatic) effect for all three major chromosomes.

There is little detail known about regulatory genes and how they interact to determine a phenotype in eukaryotes. However, in prokaryotes there are examples where an inducer molecule interacts with a repressor molecule so that the repressor molecule is changed allosterically and cannot remain attached to the DNA. The inducer molecule of the lac operon, lactose, operates in this manner although a number of analogues can carry out the same function even more effectively. If it is assumed that two different genes are potentially mutable to forms which can produce such an inducer or similarly modify an inducer, and it is assumed that a more efficient inducer is advantageous, then one dose of a favourable allele at either the regulatory gene $R_{A}$ or $R_{B}$ is capable of producing enough inducer to turn on the

TABLE 2

An example of the fitnesses where either one of two regulatory loci $\left(\mathrm{R}_{\mathrm{A}}\right.$ and $\left.\mathrm{R}_{\mathrm{B}}\right)$ is capable of increasing the fitness by turning on a producer gene

$\begin{array}{lccc} & R_{A}^{\prime} R_{A}^{\prime} & R_{A}^{\prime} R_{A} & R_{A} R_{A} \\ R_{B}^{\prime} R_{B}^{\prime} & 1+s & 1+s & 1+s \\ R_{B}^{\prime} R_{B} & 1+s & 1+s & 1+s \\ R_{B} R_{B} & 1+s & 1+s & 1\end{array}$

producer gene regulated by these genes and implies the dominance of the favourable mutants (table 2). These fitnesses could of course lead to a quite fast change in mean fitness and constitute further support for the notion that regulatory gene change may be selectively favoured under situations of rapid and dramatic adaptation. In the future as particular regulatory systems are studied in detail, the multilocus selection models can be applied to determine the rate of genetic response (Hedrick et al., 1978).

\section{(iii) Higher mutation rate}

Mutations at regulatory loci can be thought of as at least two types: point mutations in receptor, integrator, or other regulatory genes and changes in the order of genes through chromosomal mutation (McKusick and Ruddle, 1977). The rate of chromosomal rearrangement may be about $10^{-3}$ per 
genome (White, 1978), much higher than the rate of producer gene mutation. Although this is not specific to the site in question, it does allow an additional source of mutation for regulatory genes.

The mutation rate to favourable alleles at regulatory loci may be larger for several other reasons. The total amount of DNA, summing over all loci which have a regulatory function for a particular phenotype, may be much larger than the amount of DNA in the structural genes. If so and the point mutation rate is a function of the length of the nucleotide sequence, then regulatory loci could have a higher mutation rate than the structural loci in a particular system. Also, the probability of a phenotypic effect due to a point mutation in a regulatory region may be higher. Some receptor regions may be palindromic and recognise symmetric molecules (Dickson et al., 1975). Any change in these structures may result in ineffective repression of a producer gene. When or where more of the producer gene product is advantageous, then the mutant would be favoured.

There are two ways a higher mutation rate for the regulatory genes could lead to an evolutionary advantage. First, because of a higher mutation rate, the initial gene frequency of the favourable alleles may be higher. Secondly, a higher mutation rate may manifest itself in a shorter waiting time until a new favourable mutant can occur. The mean waiting time can be envisaged as a function of the product of the population size and the mutation rate, so that for a given population size the mean waiting time is shorter when there is a higher mutation rate.

These two effects are illustrated in fig. 4 . The solid line indicates the fitness as given in fig. 2 for a gene with an initial frequency of $0 \cdot 01$. The first effect is shown by broken line $\mathrm{X}$ where the initial frequency is assumed to be $0 \cdot 1$ because of higher mutation rate. Obviously, the fitness of the population

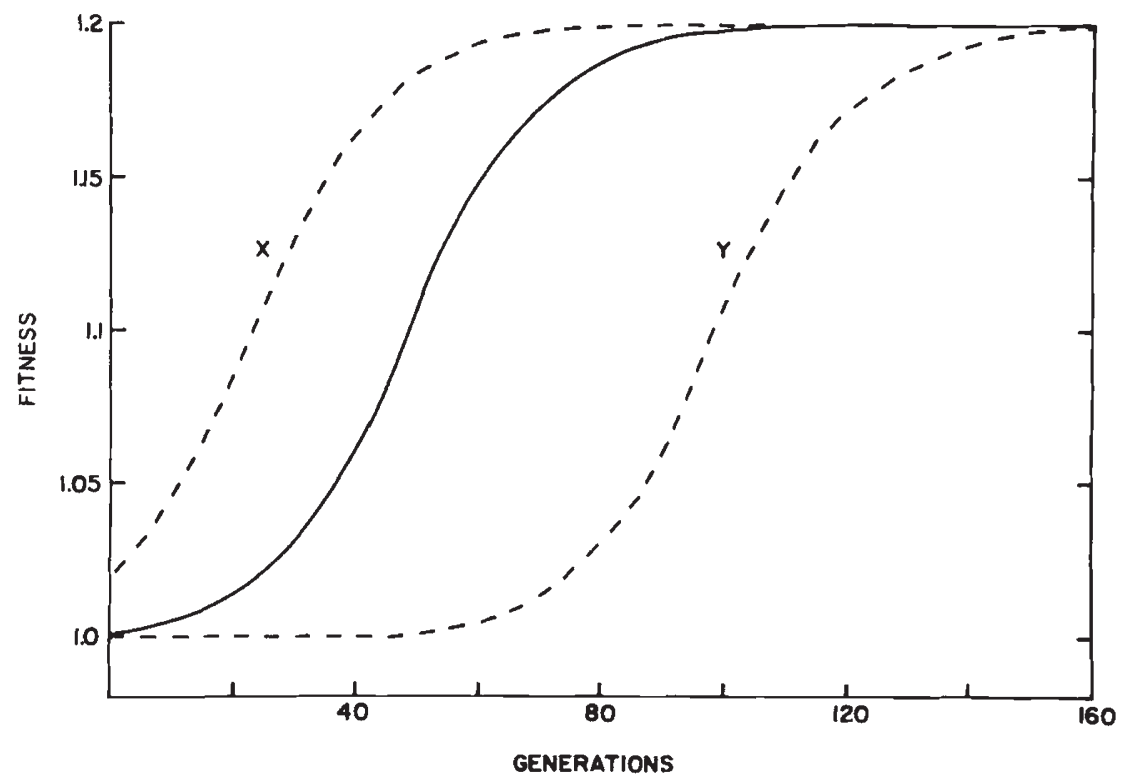

FIG. 4.-A comparison of the change in fitness when there is a higher initial gene frequency (broken line $\mathrm{X}$ ) and a 50 generation waiting time for a favourable mutant (broken line $\mathrm{Y}$ ). 
nears its maximum much more quickly because of this higher initial frequency. The other effect is given by broken line $Y$. If the solid line is compared with this line, then the difference is a 50 generation longer waiting time before selection can begin. Obviously, the population with the shorterwaiting time (due to the higher rate of mutation) will have a large adaptive advantage. If, for example, the mutation rate is tenfold higher for a regulatory gene, then the waiting time would be approximately one-tenth that of the producer gene model.

\section{(iv) Greater dominance}

There are several examples of dominance at regulatory loci. McDonald and Ayala (1978) and Barnes and Birley (1978) observed dominance of the third chromosome variants affecting ADH activity is Drosophila melanogaster. In addition, Nair et al. (1977) observed dominance for esterase phenotypes in crosses between two species of Hawaiian Drosophila which seems to show a regulatory difference. In contrast, it is noteworthy that producer loci coding for enzymes have generally been found to be additive in terms of total activity (Gillespie and Langley, 1974), i.e., the heterozygote is nearly intermediate between the two homozygotes. This is not to say that regulatory genes cannot be additive. Indeed the cis-active variants of Dickinson (1978) appear to be clearly additive in their effect. Additivity, however, is most likely to be associated with regulatory receptor sites while the effects of control genes that code for regulatory proteins may most often be dominant (Lewin 1974).

It has been shown, for example, that only a small amount of repressor molecule is necessary for gene control in prokaryotes. Assuming negative gene control, in a situation where it is advantageous to turn on a producer gene earlier, then an allele at the repressor gene which is turned on earlier would be dominant (go to receptor sites for both producer alleles). When there is positive control, then the molecules compete for attachment and the more successful would be dominant. For example, in prokaryotes it is known that regulatory gene mutations that code for activator proteins that bind more efficiently to operator sites are generally dominant to the wild type allele. Recent studies suggest that positive gene control may be a common feature of eukaryotic regulation. For example, non-histone chromosomal proteins are believed to play a major role in eukaryotic regulation (Stein and Stein, 1976). Several recent studies suggest that these proteins exert positive gene control (reviewed in Stein and Kleinsmith, 1975).

To illustrate the advantage of dominance of favourable alleles, assume that $s_{1}=\frac{1}{2} s_{2}$ or that the per locus advantage is the same for both models but that the maximum is higher for producer gene evolution and that the initial gametic frequencies and producer gene fitnesses are the same as above. However, assume the fitness of the heterozygote $R_{1} R_{2} A_{1} A_{1} B_{1} B_{1}$ to be equal to $R_{2} R_{2} A_{1} A_{1} B_{1} B_{1}$. Results of this simulation are given in fig. 5 . Again the fitness increases more quickly for the regulatory model, and it is over 90 generations before the producer gene model has an equal mean fitness. This differential rate of response can also be understood in terms of the amount of additive genetic variance because the dominance in the regulatory model results in the initial additive genetic variance being slightly 


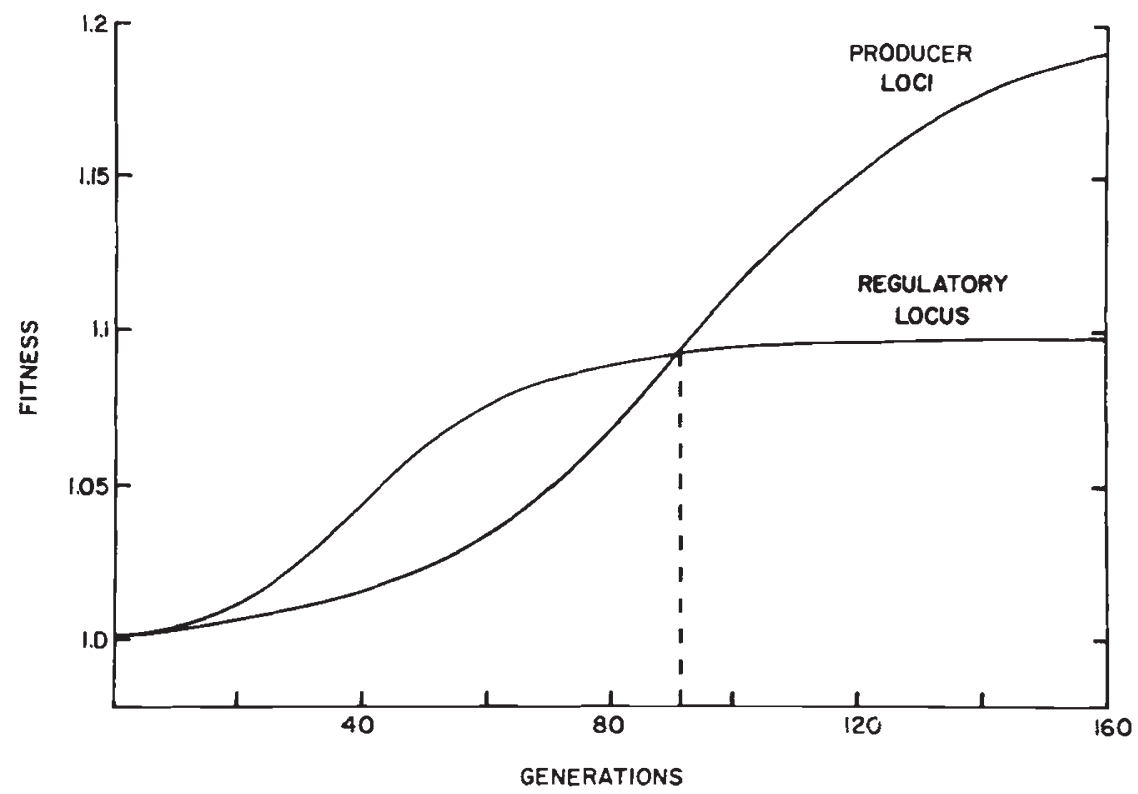

FIG. 5.-A comparison of the change in fitness for an example where there is dominance of the favourable allele at the regulatory locus and additivity for two producer loci.

higher. Furthermore, since the gene frequency change is also faster, the additive genetic variance increases quickly for the regulatory model. Once again this is consistent with the hypothesis that regulatory gene change may be selectively favoured in situations requiring rapid adaptation.

\section{IMPLICATIONS}

Verbal arguments as well as both direct and indirect experimental evidence have recently been offered in support of the notion that changes in genetic regulation may play a critical role in the evolution of eukaryotes. An important question facing evolutionary geneticists is why, and under what conditions, regulatory change may be selectively favoured over producer gene change and vice versa.

In this paper we explored the evolutionary genetic consequences of some generally accepted properties of eukaryotic regulatory systems. Based upon a hierarchical genomic structure in which regulatory genes are by definition those loci controlling the timing or expression of other genes, our model predicts that changes in genetic regulation would be the favoured genetic strategy for a population adapting to a sudden and substantial environmental change. Based upon the same assumptions the model predicts that regulatory change would not likely be favoured in situations where "adaptive fine tuning" is required. In this situation, evolution would most likely progress via changes on the producer gene level.

It is impossible at present to test these predictions directly, for techniques to quantify accurately regulatory differences in a mass survey remain to be developed. It is, however, suggestive that those groups of species 
which are believed to have radiated quickly often display relatively little differentiation on the producer gene level while showing major phenotypic variation (e.g., King and Wilson, 1975; Sene and Carson, 1977; Turner et al., 1979). Although a final answer must await further experimentation, it is tempting to speculate that the observed phenotypic differences largely reflect changes in gene regulation. In contrast, those species which are believed to have evolved more gradually, do generally display a degree of producer gene differentiation consistent with their level of divergence (for review, see Ayala, 1975). In addition the degree of producer gene differentiation between these species generally correlates with observable differences on the phenotypic level.

The evolutionary genetic model used here assumes that evolution proceeds so that fitness is increased over time (genetic load reduced) and that this occurs in the minimal time possible. It is probably true that evolution does not always proceed to maximise fitness (reduce genetic load) in a given environment. For example, genetic drift may introduce chance deviations which result in a decreased fitness value. Secondly, fitness may not always be increased by the fastest route possible. For example, gametic disequilibrium generated via multilocus selection may slow down the rate of response. However, it is initially useful to assume evolution proceeds to maximise fitness as quickly as possible. Constraints such as genetic drift, gametic disequilibrium or other factors can be added as refinements or extensions to the basic model given here.

The regulatory model described here is based upon present views of the organisation and regulation of the eukaryotic genome. Obviously, this view will change as additional information is accrued. However, the basic assumption of the hierarchical mode of control seems secure and it is largely upon this assumption that our major predictions rest. The model is not intended as a final view on genetic strategies of adaptive evolution. It is intended as a reasonable first step and has enabled us to make specific predictions which are, in principle, subject to experimental test.

Acknowledgements.--We are grateful for comments by James Crow, John Grula, Richard Lewontin, Ross MacIntyre, Jeff Mitton, Elizabeth Murray, Martin Tracy, and Alan Wilson and for the discussion following our paper at the Evolution meeting in 1978. This work was in part supported by NSF Grant DEB-7815466 to J.M.

\section{REFERENCES}

ASHBURNER, M. 1970. Function and structure of polytene chromosomes during insect development. Adv. Insect Physiol., 7, 1-95.

AVISE, J. C. 1974. Systematic value of electrophoretic data. Syst. Zool., 23, 465-481.

AVISE, J. C. 1976. Genetic differentiation during speciation. In Molecular Evolution, ed. F. J. Ayala. Sinauer Assoc., Sunderland, Mass., 106-122.

AYALA, F. J. 1975. Genetic differentiation during the speciation. Evol. Biol., 8, 1-78.

BAKER, W. K. 1978. A genetic framework for Drosophila development. Ann. Rev. Genet., 12, 451-470.

BARNES, B. W., AND BIRLEY, A. J. 1978. Genetical variation for enzyme activity in a population of Drosophila melanogaster. IV. Analysis of alcohol dehydrogenase activity in chromosome substitution lines. Heredity, 40, 51-57.

BRITTEN, R. J., AND DAVIDSON, E. H. 1969. Gene regulation for higher cells: A theory. Science, 165, 349-357.

DICKINSON, w. J. 1978. Genetic control of enzyme expression in Drosophila: a locus influencing tissue specificity of aldehyde oxidase. J. Exp. Zool., 260, 333-342. 
DICKSON, R. C., ABELSON, J., BARNES, W. M., AND REZNIKOFF, W. S. 1975. Genetic regulation: The lac control region. Science, 187, 27-35.

FISHER, R. A. 1958. The Genetical Theory of Natural Selection. Second edition. Dover, New York.

GARCIA-BELLIDO, A. 1975. Genetic control of wing disc development. In Cell Patterning, eds. R. Porter and J. Rivers. Associated Scientific Publishers, New York, 161-182.

GARCIA-BELlido, A. 1977. Homoeotic and atavic mutations in insects. Amer. Zool., 17, 613-329.

Gillespie, J. A., AND LANGley, C. H. 1974. A general model to account for enzyme variation in natural populations. Genetics, 76, 837-948.

GoldsCHMIDT, R. 1930. The Material Basis of Evolution. Yale Univ. Press, New Haven, Conn.

HEDRICK, P. W., JAIN, S., AND HOLDEN, L. 1978. Multilocus systems in evolution. Evol. Biol., 11, 101-184.

HOOD, L. E., WILSON, J. H., AND WOOD, W. B. 1975. Molecular Biology of Eucaryotic Cells. W. A. Benjamin, Inc., Menlo Park, California.

KERR, W. E., AKAHIRA, Y., AND CAMARGO, C. A. 1975. Sex determination in bees. IV. Genetic control of juvenile hormone production in Meliponaquadrifasciata (Apidae). Genetics, 81, 749-756.

KING, M. C., AND WILSON, A. C. 1975. Evolution at two levels: Molecular similarities and biological differences between humans and chimpanzees. Science, 188, 107-116.

LAURIE-AHLBERG, C. C., MARONI, G. P., BEWLEY, G. C., LUCHESI, J. C., AND WEIR, B. S. 1980. Quantitative genetic variation of enzyme activities in natural populations of Drosophila melanogaster. Proc. Natl. Acad. Sci. 77, 1073-1077.

LEWIN, B. 1974. Gene expression-1. Bacterial Genomes. Wiley, New York.

LEWIS, E. B. 1978. A gene complex controlling segmentation in Drosophila. Nature, 276, $565-560$

LIN, E. C. C., HACKING, A. J., AND AQUilar, J. 1976. Experimental models of acquisitive evolution. Bioscience, 26, 458-555

MARONI, G. 1978. Genetic control of alcohol dehydrogenase levels in Drosophila. Biochem. Genetics, 16, 509-523.

MacINTYRE, R., AND O'BRIEN, S. 1976. Interacting gene-enzyme in Drosophila. Ann. Rev. Genet., 10, 281-318.

McDONALD, J. F., AND AYALA, F. J. 1978. Genetic and biochemical basis of enzyme activity variation in natural populations. I. Alcohol dehydrogenase in Drosophila melanogaster. Genetics, 89, 371-388.

McDONALD, J. F., CHAMBERS, G. K., DAVID, J., AND AYALA, J. F. 1977. Adaptive response due to changes in gene regulation: a study with Drosophila. Proc. Natl. Acad. Sci., 74, $4562-4566$.

McKUSICK, V. A., AND RUDDLE, F. H. 1977. The status of the gene map of the human chromosomes. Science, 196, 390-405.

NAIR, P. S., CARSON, H. L., AND SENE, F. M. 1977. Isozyme polymorphism due to regulatory influence. Amer. Natur., 111, 789-791.

RADINSKY, L. 1978. Do albumin clocks run on time? Science, 200, 1182-1183.

SELANDER, R. K., AND JOHNSON, W. E. 1973. Genetic variation among vertebrate species. Ann. Rev. Ecol. Syst., 4, 75-91.

SENE, F. M., AND CARSON, H. L. 1977. Genetic variation in Hawaiian Drosophila. IV. Allozymic similarity between $D$. silvestris and $D$. heteroneura from the island of Hawaii. Genetics, 86, 187-198.

SIMPSON, G. G. 1944. Tempo and Mode in Evolution. Columbia University Press, New York. SIMPSON, G. G. 1953. The Major Features of Evolution. Columbia University Press, New York.

SOLL, D. 1979. Timers in developing systems. Science, 203, 841-849.

STEBbins, G. L. 1969. The Basis of Progressive Evolution. Univ. North Carolina Press, Chapel Hill.

STEIN, G. S., AND KLEINSMITH, L. J. 1975. Chromosome Proteins and Their Role in the Regulation of Gene Expression. Academic Press, New York.

STEIN, G.S., AND STEIN, J. L. 1976. Chromosomal proteins: their role in the regulation of gene expression. Bioscience, 26, 488-498.

THOMPSON, J. N., ASHBURNER, M., AND WOODRUFF, R. C. 1977. Presumptive control mutation for alcohol dehydrogenase in Drosophila melanogaster. Nature, $270,363$. 
TURNER, J. R. G., JOHNSON, M. S., AND EANES, W. F. 1979. Contrasted modes of evolution in the same genome: Allozymes and adaptive change in Heliconius. Proc. Natl. Acad. Sci., 76, 1924-1928.

VALENTINE, J., AND CAMPBELl, C. 1975. Genetic regulation and the fossil record. Amer. Sci., 63, 673-680.

WALlACE, B. 1963. Genetic diversity, genetic uniformity and heterosis. Canad. J. Genet. Cytol., 5, 239-253.

WARD, R. 1975. Alcohol dehydrogenase activity in Drosophila melanogaster: a quantitative character. Genet. Res., 26, 81-93.

WhiTE, M. J. D. 1978. Modes of Speciation. W. H. Freeman, San Francisco.

WILSON, A. C. 1975. Evolutionary importance of gene regulation. Stadler Symp., 7, 117-133. WRIGHT, S. 1969. Evolution and the Genetics of Population. II. The Theory of Gene Frequencies. Univ. Chicago Press, Chicago.

ZUCKERKANDL, E. 1963. Perspectives in molecular anthropology. In Classification and Human Evolution, ed. S. L. Washburn. Aldine Publ. Co., Chicago, 243-272. 